\title{
Microemulsion as Sample Preparation for Direct Flame Atomic Absorption Spectrometry (FAAS) Determination of Total Iron in Crude and Refined Vegetable Oils
}

\author{
Marília B. Galuch, ${ }^{a}$ Angélica F. B. Piccioli, ${ }^{a}$ Eduardo Sobieski Neto, ${ }^{a}$ Natália Fier, ${ }^{b}$ \\ Nayara C. Saldan ${ }^{a}$ and Edivaldo E. Garcia ${ }^{*, a}$ \\ ${ }^{a}$ Departamento de Química and ${ }^{b}$ Complexo de Centrais de Apoio à Pesquisa (COMCAP), \\ Universidade Estadual de Maringá (UEM), 87020-900 Maringá-PR, Brazil
}

\begin{abstract}
This work proposed a novel, relatively low-cost and rapid analytical method using microemulsion as sample preparation to determine iron $(\mathrm{Fe})$ in vegetable oils by flame atomic absorption spectrometry technique (FAAS). The vegetable oil microemulsions were obtained by mixing appropriate proportions of the crude and refined vegetable oil, Triton ${ }^{\circledR} \mathrm{X}-100$, 1-propanol and nitric acid 50\% ( $\left.\mathrm{v} \mathrm{v}^{-1}\right)$. Moreover, an external calibration method was established using aqueous Fe standards instead of expensive and unstable organometallic standards. The limits of detection and quantification were 0.40 and $1.3 \mathrm{mg} \mathrm{kg}^{-1}$ of oil, respectively. The accuracy was checked by recovery studies (with recoveries ranging $84-105 \%$ ) and by Fe determination in digested vegetable oil samples by inductively coupled plasma optical emission spectrometry (ICP OES) as comparative procedure. The proposed analytical method was efficient to determine $\mathrm{Fe}$ in crude and refined vegetable oils from various vegetable sources, besides being suitable for routine analyses due to its simplicity.
\end{abstract}

Keywords: iron, direct analysis, flame atomic absorption spectrometry, microemulsion, vegetable oil

\section{Introduction}

Iron $(\mathrm{Fe})$ is one of the most abundant elements in the earth's crust. ${ }^{1}$ This mineral naturally occurs at low concentrations in vegetable products, such as refined and crude vegetable oils. ${ }^{2}$ Vegetable oils can be contaminated with $\mathrm{Fe}$ and other transition metals, during the steps of oil production, transportation and packaging, as well as during the cultivation of oilseeds with irrigation water, ${ }^{3}$ fertilizers and pesticides. ${ }^{4}$

One of the main issues caused by the presence of trace Fe levels in vegetable oils is the accelerated decrease in both oil quality and oxidative stability, due to catalyzed lipid oxidation, ${ }^{5}$ because $\mathrm{Fe}$ is one of the most active prooxidant transition metals in vegetable oils. ${ }^{6}$ Lipid oxidation leads to the formation of primary oxidation products, such as hydroperoxides, which are decomposed into secondary oxidation products, such as aldehydes, ketones and alcohols. Secondary oxidation products have negative implications for sensory characteristics (smell and taste,

*e-mail: edivaldogarcia@yahoo.com.br for example) and shelf life of vegetable oils, as well as for human health. ${ }^{7}$ Therefore, monitoring Fe concentration throughout the manufacturing process of edible vegetable oils is highly desirable from the technological, nutritional, and toxicological perspectives. According to Codex Alimentarius, ${ }^{8}$ the recommended maximum acceptable $\mathrm{Fe}$ levels in refined and crude vegetable oils that are presented in a state for human consumption are 1.5 and $5.0 \mathrm{mg} \mathrm{kg}^{-1}$, respectively.

Traditional analytical methods to determine trace $\mathrm{Fe}$ in vegetable oils are mainly based on the use of instrumental techniques, such as flame atomic absorption spectrometry (FAAS), ${ }^{9,10}$ electrothermal atomic absorption spectrometry (ETAAS),${ }^{11}$ inductively coupled plasma optical emission spectrometry (ICP OES) $)^{2,12}$ and inductively coupled plasma mass spectrometry (ICP-MS). ${ }^{13}$ In most instances, these techniques have been applied in association with various types of sample pretreatments before the analysis, aimed to reduce matrix and spectral interferences and increase the availability of the trace metals for determination in viscous liquid samples containing a high organic content, such as vegetable oils. Conversely, limited studies have 
proposed procedures that directly analyze vegetable oils for Fe determination. ${ }^{14,15}$

Direct analysis of vegetable oils for the determination of Fe or other metals is not a simple task. The difficulty is mainly due to the low levels of Fe in vegetable oils, as well as to the other problems caused by matrix interferences, ${ }^{2,9,16}$ such as the high organic content and high viscosity of these matrices. ${ }^{2}$ These matrix properties can cause destabilization of the inductively coupled plasmas and flames employed as atomization systems in ICP and FAAS techniques, respectively. Besides, direct analysis may cause problems with the process of introduction of samples into the atomization systems (when graphite furnace atomic absorption spectroscopy (GF AAS) or pneumatic nebulizers are used). ${ }^{17}$ Furthermore, the complex matrices of vegetable oils also hamper the establishment of an appropriate calibration procedure for their direct analysis. ${ }^{2}$

Most of the sample treatment procedures applied in the analysis of vegetable oils are based on liquid-liquid extraction, ${ }^{10}$ acid extraction, ${ }^{11,18}$ extraction induced by emulsion breaking, ${ }^{13}$ ultrasound assisted extraction, 5,6 emulsification $^{19,20}$ and microemulsification. ${ }^{3}$ Among these, microemulsification has emerged as a suitable and promising sample pretreatment procedure for direct analysis of samples with a high organic content, such as vegetable oils, diesel, ${ }^{21}$ biodiesel, ${ }^{22-25}$ lubricating oil, ${ }^{26,27}$ and fuels. ${ }^{28}$

Microemulsions can be defined as thermodynamically stable, optically transparent ${ }^{3,23,25,27-31}$ and microscopically homogeneous systems, composed of appropriate amounts of aqueous and oil phases and surfactant and/or co-surfactant. . $^{31,32}$ These systems have some characteristic properties, such as low viscosity ${ }^{23,28}$ and the capacity to solubilize both polar (aqueous) and nonpolar (oil soluble) substances. ${ }^{31,33}$ Two of the main advantages of using microemulsification for sample preparation are associated with its simplicity and the possibility to use aqueous standards for preparing calibration solutions instead of using unstable organometallic standards. ${ }^{3,24}$ From the environmental and toxicological perspectives, the application of microemulsification as a sample preparation method for direct analysis of samples containing high lipid contents is attractive because it allows the direct analysis without requiring any dilution with relatively toxic organic solvents. ${ }^{24}$

Therefore, this work proposes a novel routine analytical procedure for the determination of $\mathrm{Fe}$ at trace amounts in samples of various crude and refined (edible) vegetable oils, using a microemulsion-based sample preparation method and conventional FAAS as the measurement technique. To the best of our knowledge, this study is the first to propose a sample preparation procedure based on microemulsification for $\mathrm{Fe}$ determination in crude and refined vegetable oil samples using the conventional FAAS technique. Moreover, the conventional FAAS technique is very inexpensive compared to both the modern high-resolution continuum source flame atomic absorption spectrometry (HR-CS FAAS), as described by Nunes et al., ${ }^{3}$ and GF AAS which is necessary in recommended methods (IUPAC 2.631, ${ }^{34}$ ISO 8294: 1994, ${ }^{35}$ AOAC $990.05^{36}$ or AOCS Ca 18b-91) ${ }^{37}$ for Fe determination in vegetable oils.

The proposed method was evaluated in terms of microemulsions stability, precision (relative standard deviation (RSD), \%), limits of detection (LOD) and quantification (LOQ), linear range and accuracy (through recovery tests and by determination of $\mathrm{Fe}$ in digested vegetable oil samples by ICP OES as comparative procedure). It can be considered very useful to be applied in routine analyses and during the oil refining process quality control, especially because of its low-cost, simplicity and little sample handling.

\section{Experimental}

\section{Reagents, solutions and samples}

Ultrapure water (obtained by a Milli-Q ${ }^{\circledR}$ water purification system; Millipore, Billerica, MA, USA) and nitric acid of high purity (obtained by a sub-boiling distillation system; Milestone DuoPUR, Sorisole, Italy) were used throughout all the experiments. All glassware, pipette tips, PFA-Teflon digestion vessels, and polypropylene flasks were soaked in a $10 \%\left(\mathrm{v} \mathrm{v}^{-1}\right)$ nitric acid (65\%, Sigma-Aldrich, Germany) bath for at least $24 \mathrm{~h}$, then, rinsed at least three times with ultrapure water and allowed to dry at room temperature before use.

Light mineral oil (Tedia, Rio de Janeiro, Brazil), propan1-ol ( $\geq 99.5 \%$, Sigma-Aldrich, Germany) and Triton ${ }^{\circledR}$ X-100 (Merck, Darmstadt, Germany) were used without further purification, for preparing the microemulsions. Inorganic aqueous reference Fe solutions for analytical calibration were prepared by appropriate dilutions of $1000 \mathrm{mg} \mathrm{L}^{-1}$ standard Fe stock solution (Specsol, São Paulo, Brazil).

Crude and refined soybean, corn, sunflower and canola oils were obtained from Cocamar (vegetable oil factory; Maringá, Paraná, Brazil), and refined cottonseed oil was purchased from a local market (Maringá, Paraná, Brazil).

\section{Flame atomic absorption spectrometry}

The total $\mathrm{Fe}$ concentrations in crude and refined vegetable oil microemulsion samples were directly 
measured in microemulsions by using an atomic absorption spectrometer (Varian 240FS, Mulgrave, Australia), equipped with a deuterium background correction system. This correction approach permitted to circumvent eventual spectral interferences caused mainly by scattering effects and incomplete atomization of the molecular carbon residues formed in the flame as a consequence of the relatively high carbon content of the vegetable oil microemulsions.

A multi-element $\mathrm{Cu} / \mathrm{Fe} / \mathrm{Mn} / \mathrm{Zn}$ hollow cathode lamp (Varian, Mulgrave, Australia) was used as the radiation source, and an air/acetylene $(99.7 \%$, Linde, Brazil) flame was used for atomization. All atomic absorbance measurements were performed in triplicate, and their acquisitions were based on the peak height mode. The operational spectrometer parameters are: wavelength $(248.3 \mathrm{~nm})$, lamp current $(10.0 \mathrm{~mA})$, spectral resolution $(0.2 \mathrm{~nm})$ and flame composition of air/ $\mathrm{C}_{2} \mathrm{H}_{2}$ $\left(13.5 / 2 \mathrm{~L} \mathrm{~min}^{-1}\right)$.

Sample preparation, microemulsion stability and calibration method evaluation

The microemulsions were prepared based on Amais et al. ${ }^{24}$ by the sequential addition: approximately $0.25 \mathrm{~g}$ of sample (crude or refined vegetable oil), $4.40 \mathrm{~mL}$ propan-1-ol (as cosolvent), $250.0 \mu \mathrm{L}$ Triton ${ }^{\circledR} \mathrm{X}-100$ (as surfactant), and $100.0 \mu \mathrm{L}$ of $50 \%\left(\mathrm{v} \mathrm{v}^{-1}\right)$ nitric acid (as aqueous phase) into a $15 \mathrm{~mL}$ graduated polypropylene flask (Corning ${ }^{\circledR}$, New York, USA). The mixture was vortexed (IKA Vortex 1, Germany) for 2 min to obtain a homogeneous, stable and transparent microemulsion.

The stability of the microemulsion samples was checked by FAAS measurement of the absorbance signals for $\mathrm{Fe}$ (every $30 \mathrm{~min}$ for $8 \mathrm{~h}$ ) of crude and refined soybean, corn, canola and sunflower microemulsions spiked with 0.5 and $1.0 \mathrm{mg} \mathrm{L}^{-1}$ of Fe.

A calibration method evaluation was performed in order to establish an appropriate strategy for $\mathrm{Fe}$ determination in the crude and refined vegetable oil microemulsions, taking into account the possible existence of matrix effects, of the chemical (different constitutions of vegetable oils) or physical type (different viscosities of vegetable oil microemulsions that could affect their aspiration rate and, consequently, the amount of $\mathrm{Fe}$ introduced into the flame).

For that, three external calibration curves (using solutions $\mathrm{A}, \mathrm{B}$ and $\mathrm{C}$ as calibration media) and four calibration curves using the standard addition method (for crude soybean, sunflower, canola and corn oils) were obtained in order to compare their slopes (sensitivities) and to select the optimum calibration media for Fe determination in crude and refined vegetable oil microemulsions. All comparisons were made considering the same range of concentrations (0.1-1.0 $\left.\mathrm{mg} \mathrm{L}^{-1} \mathrm{Fe}\right)$. The constitution of solutions A, B and $\mathrm{C}$ are shown in Table 1.

Crude vegetable oils were chosen to perform the calibration method evaluation because their matrices could lead to more pronounced interferences than refined vegetable oil matrices.

\section{Accuracy evaluation}

Recovery test was performed in crude and refined vegetable oil microemulsions spiked with $0.1,0.2$ and $0.5 \mathrm{mg} \mathrm{L}^{-1}$ of $\mathrm{Fe}$, in order to investigate the accuracy of the proposed method. The additions of Fe were carried out together with the aqueous phase of the microemulsion.

Additionally, a comparative procedure was performed also for checking the accuracy of the results. For that, $\mathrm{Fe}$ concentrations were determined in digested vegetable oil samples by ICP OES.

\section{Comparative procedure (sample preparation and ICP OES measurements)}

The digestion of vegetable oil samples was performed in a microwave digestion system (CEM MARS Xpress, Matthews, USA), equipped with $55 \mathrm{~mL}$ perfluoroalkoxy (PFA)-Teflon ${ }^{\circledR}$ digestion vessels, according to the conditions shown in Table 2.

Table 1. Constitution of the solutions A, B and C (as calibration media), and sample microemulsion

\begin{tabular}{lccccc}
\hline Calibration medium & Propan-1-ol $/ \mathrm{mL}$ & Vegetable oil ${ }^{\mathrm{a}} / \mathrm{mg}$ & Light mineral oil / mg & Triton ${ }^{\oplus} \mathrm{X}-100 / \mu \mathrm{L}$ & $\begin{array}{c}\text { Nitric acid } \\
50 \%(\mathrm{v} \mathrm{v})^{\mathrm{b}} / \mu \mathrm{L}\end{array}$ \\
\hline A & 4.40 & - & 0.250 & 0.250 & 0.100 \\
B & 4.65 & - & - & 0.250 & 0.100 \\
C & 4.90 & - & - & - & 0.100 \\
Sample microemulsion & 4.40 & 0.250 & - & 0.250 & 0.100 \\
\hline
\end{tabular}

${ }^{\mathrm{a} C r u d e}$ soybean, sunflower, corn and canola oils; ${ }^{\mathrm{b}}$ the aqueous Fe standards were added to media A, B and C and microemulsions by the nitric acid solution. 
Table 2. Microwave assisted acid digestion conditions used for the crude and refined vegetable oil samples

\begin{tabular}{lccccc}
\hline \multirow{2}{*}{ Step } & Power $/ \mathrm{W}$ & Power $/ \%$ & Temperature $/{ }^{\circ} \mathrm{C}$ & \multicolumn{2}{c}{ time $/$ min } \\
\hline 1 & 960 & 100 & 170 & Ramp & Hold \\
\hline 2 & 960 & 100 & 170 & 10 & - \\
3 & 0 & 0 & 25 & 15 & - \\
\hline
\end{tabular}

For this, approximately $0.25 \mathrm{~g}$ of crude and refined vegetable oil samples was digested with nitric acid $(5.0 \mathrm{~mL})$ and $30 \%\left(\mathrm{v} \mathrm{v}^{-1}\right)$ hydrogen peroxide $(3.0 \mathrm{~mL})$ (Merck, Darmstadt, Germany), in a $50 \mathrm{~mL}$ sealed PFA-Teflon vessel, using the conditions described above in the instrumentation section. After the cooling down step, digested sample solutions were carefully transferred to polypropylene flasks, and their final volumes were adjusted to $20.0 \mathrm{~mL}$ with ultrapure water. Finally, the total $\mathrm{Fe}$ contents of the digested sample solutions were determined by ICP OES.

A simultaneous dual view ICP OES (PerkinElmer Optima 8300, Shelton, USA), with two solid-state sulfur chemiluminescence detectors, was employed in the comparative procedure after the samples digestion. For the axially viewed plasma mode, the emission intensities of Fe were measured at $238.204 \mathrm{~nm}$ (ionic line), according to the manufacturer recommended operating conditions for plasma power $(1.3 \mathrm{~kW})$, with the nebulizer, plasma and auxiliary argon flow rates at $0.65,8.00$ and $0.20 \mathrm{~L} \mathrm{~min}^{-1}$, respectively.

\section{Results and Discussion}

\section{Microemulsion stability}

The stabilities of crude and refined vegetable oil microemulsions were checked to verify the maximum duration that the total added $\mathrm{Fe}$ concentrations in the microemulsions remained available for accurate analyte quantification. Furthermore, the microemulsions were also visually inspected for transparency and homogeneity. Crude and refined corn, canola, sunflower, and soybean oil microemulsion samples were spiked with 0.5 and $1.0 \mathrm{mg} \mathrm{L}^{-1}$ aqueous standard Fe solutions, and the stabilities were then evaluated by measuring absorbance values for $\mathrm{Fe}$ at each predefined time interval (over $8 \mathrm{~h}$ ). Stabilities for $\mathrm{Fe}$ in the microemulsions were considered analytically suitable when the RSD for the Fe absorbance signals measured at the predefined time periods did not exceed $10 \%$, and the results are shown in Table 3.
Table 3. Stability time (h) of crude and refined soybean, sunflower, corn and canola microemulsions spiked with 0.5 and $1.0 \mathrm{mg} \mathrm{L}^{-1}$ of $\mathrm{Fe}$

\begin{tabular}{lcc}
\hline \multirow{2}{*}{ Microemulsion } & \multicolumn{2}{c}{ Stability / $\mathrm{h}$} \\
\cline { 2 - 3 } & $0.5 \mathrm{mg} \mathrm{L}^{-1}$ & $1.0 \mathrm{mg} \mathrm{L}^{-1}$ \\
\hline Crude and refined soybean oil & 6 & 4 \\
Crude and refined sunflower oil & 6 & 4 \\
Crude and refined canola oil & 6 & 4 \\
Crude and refined corn oil & 4 & 3 \\
\hline
\end{tabular}

Based on the above consideration, it was observed (from Table 3) that the analytical signals for $\mathrm{Fe}$ in the crude and refined microemulsions fortified with 0.5 and $1.0 \mathrm{mg} \mathrm{L}^{-1} \mathrm{Fe}$, remained stable over 6 and $4 \mathrm{~h}$, respectively, for most samples, except for crude and refined corn oil microemulsions, which were stable only for 4 and $3 \mathrm{~h}$, respectively. The loss of stability, observed by a decrease in the Fe absorbance signals monitored by FAAS for every fortified microemulsion can possibly be due to a minor increase of vegetable oil microemulsion viscosities or changes in oil constitution caused by the lipid oxidation induced by autoxidation (catalyzed by $\mathrm{Fe}^{2+} / \mathrm{Fe}^{3+}$ cations) and photo-oxidation. Notably, lower absorbance signals are obtained when viscous solutions are aspirated when using FAAS because the analyte mass that reaches the flame is decreased due to the lower aspiration rates. ${ }^{38}$

Polyunsaturated fatty acids, such as those present in vegetable oils, undergo rapid lipid oxidation even at room temperature. ${ }^{39}$ Therefore, the relatively low stabilities observed for the vegetable oil microemulsions spiked with the higher $\mathrm{Fe}$ concentration can be attributed to the increased presence of prooxidant $\mathrm{Fe}^{2+} / \mathrm{Fe}^{3+}$ cations. Consequently, the $3 \mathrm{~h}$ duration, during which the analytical signals for $\mathrm{Fe}$ in the microemulsion samples remained stable, was assumed to be adequate to perform the $\mathrm{Fe}$ quantification by application of the proposed direct analysis method.

Both photo-oxidation and autoxidation can contribute to the lipid oxidation of vegetable oils. ${ }^{7}$ The use of vortex stirring for microemulsion homogenization probably contributed to an efficient incorporation of oxygen into the microemulsions, thereby increasing the polyunsaturated lipid oxidation rate. The increase in the rate of lipid oxidation can be explained due to the existence of a higher contact area between unsaturated lipids and oxygen in microemulsions, ${ }^{31}$ together with their optical transparency, which allows the light to interact directly with the lipids present in the microemulsions. ${ }^{40}$ Additionally, the relatively high oxygen solubility in vegetable oils at low temperatures ${ }^{41,42}$ can also contribute to the lipid oxidation. 
The rates of photo-oxidation catalyzed by visible light are much higher than autoxidation rates, ${ }^{43}$ and depend on the presence of metal ions in vegetable oils. ${ }^{7}$ In this context, it is possible to assume that both autoxidation and photooxidation might have affected the stability of the crude and refined vegetable oil microemulsions. However, due to the several factors that interactively influence the oxidative stability of the vegetable oil microemulsions, it is challenging to differentiate the individual effects of these factors on the mentioned lipid oxidation processes. Thus, additional studies about the crude and refined vegetable oil microemulsion stabilizations will be investigated in future works.

\section{Calibration method evaluation}

Initially, it was evaluated the use of an external calibration approach by using three different media of calibration (A, B, and C; the composition of these media are shown in Table 1) in order to establish a suitable external calibration curve for compensating and/or minimizing possible matrix effects on the determination of $\mathrm{Fe}$ in vegetable oil sample microemulsions. The occurrence of matrix effects in FAAS measurements, based on the continuous aspiration system for sample introduction, depends strongly on the differences in viscosity between calibration and sample solutions, because the aspiration efficiency is markedly dependent upon the viscosity. Therefore, it is crucial that both sample and calibration solutions have similar aspiration efficiencies, in order to guarantee the same analyte mass transport efficiencies from these solutions to the flame. This evaluation was performed by comparing the slope of each external calibration curves (obtained in three different calibration media: A, B and C) with the slope of each standard addition calibration curve (obtained by using the vegetable oil microemulsion samples), and the results are shown in Table 4.

According to Table 4, the slopes of the calibration curve prepared by using A and B media were similar. Therefore, the ratios between the slopes of external calibration curves prepared with medium A or B, and the slope of each standard addition calibration curve prepared with the crude corn, canola, sunflower and soybean oil samples were obtained. The corresponding slope ratio values obtained were 1.03, 0.92, 0.91 and 0.88 . For the same type of comparisons, calculations were carried out on the ratios between the slope of the external calibration curve prepared using medium $\mathrm{C}$, and the slope of each standard addition calibration curve prepared with the crude corn, canola, sunflower and soybean oil samples. In this instance, the corresponding calculated slope ratios were $0.97,0.87,0.86$ and 0.83 .

Besides that, the coefficient of variations between the slopes of external calibration curves prepared with medium A or $\mathrm{B}$, and the slope of each standard addition calibration curve prepared with the crude corn, canola, sunflower and soybean oil samples were 2.2, 6.1, 6.9 and 8.8\%, respectively. And, the coefficient of variations between the slope of external calibration curve prepared with media $\mathrm{C}$, and the slope of each standard addition calibration curve prepared with the crude corn, canola, sunflower and soybean oil samples were $1.9,10.2,11.0$ and $12.9 \%$, respectively.

From these results, it can be noted that the external calibration curve obtained with medium $\mathrm{C}$, compared to the curves obtained with either A or B media, presented higher variations in the sensitivity values (compared to the sensitivities of the standard addition calibration curves). Therefore, it can be concluded that both A and B media can be properly used as blank solutions in an external calibration method.

Table 4. Calibration equations obtained with the external calibration method using A, B and C media as analytical blanks to prepare the Fe standard solutions, and with standard addition method using crude corn, canola, sunflower and soybean oil microemulsion samples

\begin{tabular}{lccc}
\hline Medium & Calibration method & $\begin{array}{c}\text { Calibration equation } \\
\mathrm{y}=\mathrm{S}[\mathrm{Fe}]+\mathrm{I}\end{array}$ & Correlation coefficient $(\mathrm{r})$ \\
\hline A & external & $\mathrm{y}=(0.0654 \pm 0.0015)^{\mathrm{c}}[\mathrm{Fe}]+(0.0012 \pm 0.0004)$ & 0.9988 \\
B & external & $\mathrm{y}=(0.0654 \pm 0.0007)^{\mathrm{c}}[\mathrm{Fe}]+(0.0005 \pm 0.00002)$ & 0.9998 \\
C & external & $\mathrm{y}=(0.0617 \pm 0.0012)^{\mathrm{d}}[\mathrm{Fe}]+(0.0009 \pm 0.0008)$ & 0.9986 \\
Corn oil microemulsion & standard addition & $\mathrm{y}=(0.0634 \pm 0.0024)^{\mathrm{cd}}[\mathrm{Fe}]+(0.0121 \pm 0.0004)$ & 0.9996 \\
Soybean oil microemulsion & standard addition & $\mathrm{y}=(0.0741 \pm 0.0015)^{\mathrm{a}}[\mathrm{Fe}]+(0.0106 \pm 0.0001)$ & 0.9993 \\
Sunflower oil microemulsion & standard addition & $\mathrm{y}=(0.0721 \pm 0.0012)^{\mathrm{ab}}[\mathrm{Fe}]+(0.0128 \pm 0.0011)$ & 0.9995 \\
Canola oil microemulsion & standard addition & $\mathrm{y}=(0.0713 \pm 0.0008)^{\mathrm{b}}[\mathrm{Fe}]+(0.0021 \pm 0.0011)$ & 0.9995 \\
\hline
\end{tabular}

Calibration equation: $\mathrm{y}$ : absorbance signal; $\mathrm{S}$ and I: slope and intercept of the calibration curve, respectively; [Fe]: concentration of $\mathrm{Fe}\left(\mathrm{mg} \mathrm{L}^{-1}\right) ; \mathrm{Fe}$ calibration solution concentrations ranging from 0.10 to $1.0 \mathrm{mg} \mathrm{L}^{-1}$; results expressed as mean \pm standard deviation of three replicates. Values with different superscript letters in the same column are significantly different $(p<0.05)$ by $t$-test. 
Thus, considering the application of the proposed analytical method in routine analyses, medium B was chosen as the calibration blank for the external calibration method, since its constitution dispenses the use of the light mineral oil (added to simulate the oil matrix sample), contributing to a reduction in the organic matter (as waste) and minimization of analytical costs. Also, the slope of the external calibration curve prepared with medium B had the highest repeatability, with RSD below $1 \%$.

\section{Accuracy evaluation}

The accuracy of the proposed method was estimated by recovery test, through analysis of crude and refined canola, corn, soybean, and sunflower vegetable oil microemulsions spiked with $\mathrm{Fe}$ at three concentration levels. According to the Association of Analytical Chemists' (AOAC) Guidelines for Standard Method Performance Requirements, ${ }^{44}$ when the analyte concentration in the sample ranges 1-10 ppm, the acceptable recovery range is $80-110 \%$.

Considering that the recovery values (Table 5 ) ranged from $84-105 \%$, the proposed method showed good accuracy. Accordingly, the results confirm the method applicability for trace $\mathrm{Fe}$ determination in vegetable oil samples with different matrix complexities and from various sources, like the vegetable oils samples analyzed in this work. Moreover, the good recovery values indicated that the proposed method was not affected by matrix effects caused by possible differences in viscosities between calibration solutions and microemulsion samples, and the high organic content of the microemulsions. The potential spectral interferences (background absorption) caused by the high organic content of microemulsions during the $\mathrm{Fe}$ atomization in the flame, may have been corrected and/or minimized by using the background corrector based on a deuterium lamp.

Table 5. Recoveries (\%) for spiked vegetable oil samples (mean recovery \pm standard deviation, $\mathrm{n}=3$ )

\begin{tabular}{lccc}
\hline \multirow{2}{*}{ Oil sample } & \multicolumn{3}{c}{ Recovery /\% } \\
\cline { 2 - 4 } & $0.10 \mathrm{mg} \mathrm{L}^{-1 \mathrm{a}}$ & $0.20 \mathrm{mg} \mathrm{L}^{-1 \mathrm{a}}$ & $0.50 \mathrm{mg} \mathrm{L}^{-1 \mathrm{a}}$ \\
\hline Crude soybean oil & $89 \pm 3$ & $94 \pm 2$ & $91 \pm 2$ \\
Crude sunflower oil & $92 \pm 1$ & $92 \pm 4$ & $90 \pm 2$ \\
Crude canola oil & $104 \pm 2$ & $100 \pm 4$ & $102 \pm 1$ \\
Crude corn oil & $90 \pm 4$ & $88 \pm 3$ & $84 \pm 2$ \\
Refined soybean oil & $103 \pm 3$ & $96 \pm 4$ & $93 \pm 3$ \\
Refined sunflower oil & $99 \pm 7$ & $90 \pm 4$ & $95 \pm 2$ \\
Refined canola oil & $101 \pm 3$ & $96 \pm 5$ & $101 \pm 5$ \\
Refined corn oil & $105 \pm 6$ & $98 \pm 2$ & $93 \pm 2$ \\
\hline
\end{tabular}

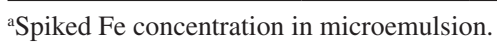

Furthermore, to perform an additional evaluation of the method accuracy, the Fe concentrations obtained from the analysis of some vegetable oil samples were compared with those detected using ICP OES after sample treatment by microwave assisted acid digestion. As shown in Table 6, the obtained Fe concentrations were in good agreement with the ICP OES results, considering that the paired $t$-test conducted at the $95 \%$ confidence level did not show significant differences.

Table 6. Determination of $\mathrm{Fe}$ in crude vegetable oil samples by using the proposed and comparative procedures based on the FAAS and ICP OES measurements, respectively (mean \pm standard deviation, $n=3$, at 95\% confidence level)

\begin{tabular}{lcc}
\hline \multirow{2}{*}{ Oil sample } & \multicolumn{2}{c}{ Fe concentration $/\left(\mathrm{mg} \mathrm{kg}^{-1}\right)$} \\
\cline { 2 - 3 } & FAAS & ICP OES \\
\hline Crude soybean oil & $2.72 \pm 0.05$ & $2.83 \pm 0.11$ \\
Crude corn oil & $3.74 \pm 0.11$ & $3.41 \pm 0.37$ \\
Crude sunflower oil & $3.67 \pm 0.19$ & $4.03 \pm 0.39$ \\
\hline
\end{tabular}

FAAS: flame atomic absorption spectrometry; ICP OES: inductively coupled plasma optical emission spectrometry.

\section{Analytical performance and application}

After verifying the applicability of the proposed method, and considering the importance of identifying the lowest Fe concentrations measurable by its application, the LOD and LOQ were estimated, based on the criteria established by the International Union of Pure and Applied Chemistry (IUPAC).$^{45}$ The LOD and LOQ were defined as $3 \mathrm{~s}_{\text {blank }} / \mathrm{b}$, and $10 \mathrm{~s}_{\text {blank }} / \mathrm{b}$, respectively, where $\mathrm{s}_{\text {blank }}$ is the standard deviation for absorbance measurements of 10 blank calibration solutions, and $\mathrm{b}$ is the slope of the external calibration curve. The method repeatability, expressed as RSD (\%), was obtained from 10 independent replicates, at three different Fe concentrations $\left(0.1,0.2\right.$ and $\left.0.5 \mathrm{mg} \mathrm{L}^{-1}\right)$ in microemulsions. The LOD, LOQ, repeatability and linear range obtained by the proposed method are shown in Table 7.

Table 8 shows the LODs found in the literature, for Fe determination in vegetable oils, by applying different analytical assays involved with the use of various procedures of sample preparation and types of instrumental techniques.

The LOD obtained in this work $\left(0.40 \mathrm{mg} \mathrm{kg}^{-1}\right)$ was similar to the LOD found by Cindric et al. ${ }^{46}\left(0.41 \mathrm{mg} \mathrm{kg}^{-1}\right)$, and was lower than LODs found by Nunes et al. ${ }^{3}$ $\left(0.62 \mathrm{mg} \mathrm{kg}^{-1}\right)^{3}$ and by Ieggli et al. ${ }^{20}\left(1.0 \mathrm{mg} \mathrm{kg}^{-1}\right)$; but higher than those found in other researches presented in Table 6. However, the proposed method is advantageous 
Table 7. Analytical parameters obtained for the Fe determination in crude and refined vegetable oil microemulsion samples by FAAS

\begin{tabular}{lc}
\hline Parameter & Value \\
\hline $\mathrm{LOD}^{\mathrm{a}} /\left(\mathrm{mg} \mathrm{kg}^{-1}\right)$ & 0.40 \\
$\mathrm{LOQ}^{\mathrm{a}} /\left(\mathrm{mg} \mathrm{kg}^{-1}\right)$ & 1.3 \\
Linear range $^{\mathrm{a}} /\left(\mathrm{mg} \mathrm{kg}^{-1}\right)$ & $1.3-160.0$ \\
Repeatability RSD / \% & $1.0-5.7$ \\
\hline
\end{tabular}

${ }^{\mathrm{a}}$ Data in $\mathrm{m} \mathrm{kg}^{-1}$ of oil samples were calculated taken into consideration the sample dilution (amount of oil sample and total volume of microemulsion: 20-fold dilution); LOD: limit of detection, LOQ: limit of quantification; RSD: relative standard deviation.

since no special apparatus is required in sample preparation procedure for $\mathrm{Fe}$ determination (such as centrifugal, ultrasonic bath, microwave digestion system or silica gel column) in addition to using the lower-cost and conventional FAAS technique. Moreover, it attends the recommendation from Codex Alimentarius, ${ }^{8}$ maximums of 1.5 and $5.0 \mathrm{mg} \mathrm{kg}^{-1}$ of $\mathrm{Fe}$ in refined and crude vegetable oils, respectively.Thus, it can be inferred that the proposed method can be successfully applied in routine analysis for direct Fe determination, contributing to an adequate quality control of crude and refined vegetable oils.

The proposed method was applied to analyze crude and refined vegetable oils from various vegetable sources, and the $\mathrm{Fe}$ concentrations found in crude soybean, corn and sunflower oils were $2.72 \pm 0.05,3.74 \pm 0.11$ and $3.67 \pm 0.19 \mathrm{mg} \mathrm{kg}^{-1}$, respectively (shown in Table 6). In crude canola oil and refined soybean, corn, sunflower, canola and cottonseed oils the Fe concentrations found were below the LOQ.
The fact that all Fe concentrations in the analyzed refined vegetable oils were lower than the LOQ can be explained by considering that the oil refining process was effective for removing $\mathrm{Fe}^{51-53}$ contributing to reducing the occurrence of adverse effects on the oxidative stability of vegetable oils due to the presence of prooxidant $\mathrm{Fe}^{2+} / \mathrm{Fe}^{3+}$ cations.

Iron may be present in vegetable oils due to environmental factors and contaminations during the refining process. Hence, a wide range of $\mathrm{Fe}$ concentrations in these samples exists in the literature. Pehlivan et al. ${ }^{18}$ determined $0.0107-0.0195 \mathrm{mg} \mathrm{kg}^{-1}$ of Fe in refined soybean, sunflower and corn oils. He et al. ${ }^{13}$ found $0.019-0.177 \mathrm{mg} \mathrm{kg}^{-1}$ of Fe in refined soybean, sunflower, corn and canola oils. However, comparatively higher Fe concentrations can be observed in refined oils, such as 23.3 and $15.3 \mathrm{mg} \mathrm{kg}^{-1}$ for refined soybean and sunflower, respectively, ${ }^{46}$ and 8.920, 8.398 and $8.004 \mathrm{mg} \mathrm{kg}^{-1}$ for refined sunflower, corn and canola oils, respectively. ${ }^{2}$ Also, $2.80 \mathrm{mg} \mathrm{kg}^{-1}$ of Fe was reported in crude soybean oil ${ }^{51}$ which is close to the concentration found in the current work $\left(2.72 \pm 0.05 \mathrm{mg} \mathrm{kg}^{-1}\right)$ for the same type of vegetable oil. Moreover, $8.37 \mathrm{mg} \mathrm{kg}^{-1}$ of Fe in crude sunflower oil ${ }^{53}$ and $0.5-1.5 \mathrm{mg} \mathrm{kg}^{-1}$ of Fe in crude canola oil ${ }^{52}$ have been previously reported.

\section{Conclusions}

The new method proposed in this work is a suitable alternative for Fe determination in crude or refined vegetable oils, mainly because of its rapidity and simplicity. The proposed method proved to be applicable and reliable, without the need to use any relatively high-cost instrumentation for

Table 8. Limit of detection (LOD) reported in the literature for the determination of Fe in vegetable oils by different analytical procedures

\begin{tabular}{lccc}
\hline Sample treatment & Analytical technique & LOD / $\left(\mathrm{mg} \mathrm{kg}^{-1}\right)$ & Reference \\
\hline Microemulsification & FAAS & 0.40 & this work \\
MWAD & ICP OES & 0.41 & 46 \\
Emulsification & FAAS & 1.0 & 20 \\
Microemulsification & HR-CS FAAS & 0.62 & 3 \\
MWAD & ICP OES & 0.12 & 47 \\
LLE with a Schiff Base & FAAS & 0.09 & 9 \\
LLE with chelating agent & FAAS & 0.0673 & 10 \\
UAE & HR-CS FAAS & 0.061 & 5 \\
SPE & FAAS & 0.0228 & 48 \\
Saponification + UV photolysis & IC/UV-Vis detection & 0.02 & 49 \\
Direct analysis with dilution & ICP OES & 0.01 & 12 \\
Direct analysis with dilution & GF AAS & 0.0044 & 50
\end{tabular}

MWAD: microwave assisted digestion; LLE: liquid-liquid extraction; UAE: ultrasound-assisted extraction; SPE: solid-phase extraction; UV: ultraviolet; FAAS: flame atomic absorption spectrometry; ICP OES: inductively coupled plasma optical emission spectrometry; HR-CS FAAS: high resolution continuum source flame atomic absorption spectrometry; IC/UV-Vis detection: ion chromatography method with UV detection; GF AAS: graphite furnace atomic absorption spectrometry; LOD: limit of detection. 
sample preparation, except by requiring the use of FAAS as the measurement technique. Moreover, this method provides a highly attractive alternative for quality control of edible oils, during their manufacturing processes, by quantifying $\mathrm{Fe}$ in crude or refined vegetable oils. It is highly likely that the concentrations of other metals can also be determined in vegetable oils by applying the respective proposed method.

\section{Acknowledgments}

The authors are grateful to: CAPES and CNPq for the financial support and research grants, Dr Adilson de Oliveira Junior (Embrapa Soja) for the use of the microwave digestion system and for the ICP OES analyses, and to COMCAP-UEM for the use of FAAS equipment.

\section{References}

1. Al-Abadleh, H. A.; RSC Adv. 2015, 5, 45785.

2. Bakircioglu, D.; Kurtulus, Y. B.; Yurtsever, S.; Food Chem. 2013, 138, 770.

3. Nunes, L. S.; Barbosa, J. T. P.; Fernandes, A. P.; Lemos, V. A.; Walter, N. L.; Graças, M.; Korn, A.; Teixeira, L. S. G.; Food Chem. 2011, 127, 780.

4. Ansari, R.; Kazi, T. G.; Jamali, M. K.; Arain, M. B.; Wagan, M. D.; Jalbani, N.; Afridi, H. I.; Shah, A. Q.; Food Chem. 2009, 115, 318.

5. Trindade, A. S. N.; Dantas, A. F.; Lima, D. C.; Ferreira, S. L. C.; Teixeira, L. S. G.; Food Chem. 2015, 185, 145.

6. Anwar, F.; Kazi, T. G.; Saleem, R.; Bhanger, M. I.; Grasas Aceites 2004, 55, 160.

7. Choe, E.; Min, D. B.; Compr. Rev. Food Sci. Food Saf. 2006, 5 , 169.

8. Codex Alimentarius Commission; Codex Standard for Named Vegetable Oils, CODEX-STAN 210-1999. Available at http:// www.fao.org/docrep/004/y2774e/y2774e04.htm\#TopOfPage, accessed on September 29, 2017.

9. Baran, E. K.; Yaşar, S. B.; Food Anal. Methods 2013, 6, 528.

10. Tokay, F.; Bağdat, S.; J. Am. Oil Chem. Soc. 2015, 92, 317.

11. De Leonardis, A.; Macciola, V.; De Felice, M.; Int. J. Food Sci. Technol. 2000, 35, 371.

12. Chaves, E. S.; de Loos-Vollebregt, M. T. C.; Curtius, A. J.; Vanhaecke, F.; Spectrochim. Acta, Part B 2011, 66, 733.

13. He, Y. M.; Chen, J. J.; Zhou, Y.; Wang, X. J.; Liu, X. Y.; Anal. Methods 2014, 6, 5105.

14. Carbonell, V.; Mauri, A. R.; Salvador, A.; de la Guardia, M.; J. Anal. At. Spectrom. 1991, 6, 581.

15. Fischer, J. L.; Rademeyer, C. J.; J. Anal. At. Spectrom. 1994, 9 , 623.

16. Matos Reyes, M. N.; Campos, R. C.; Talanta 2006, 70, 929.
17. Lepri, F. G.; Chaves, E. S.; Vieira, M. A.; Ribeiro, A. S.; Curtius, A. J.; DeOliveira, L. C. C.; DeCampos, R. C.; Appl. Spectrosc. Rev. 2011, 46, 175.

18. Pehlivan, E.; Arslan, G.; Gode, F.; Altun, T.; Musa Özcan, M.; Grasas Aceites 2008, 59, 239.

19. Anthemidis, A. N.; Arvanitidis, V.; Stratis, J. A.; Anal. Chim. Acta 2005, 537, 271.

20. Ieggli, C. V. S.; Bohrer, D.; do Nascimento, P. C.; de Carvalho, L. M.; Food Addit. Contam., Part A 2011, 28, 640.

21. Aucélio, R. Q.; Doyle, A.; Pizzorno, B. S.; Tristão, M. L. B.; Campos, R. C.; Microchem. J. 2004, 78, 21.

22. de Jesus, A.; Silva, M. M.; Vale, M. G. R.; Talanta 2008, 74, 1378.

23. Lyra, F. H.; Carneiro, M. T. W. D.; Brandão, G. P.; Pessoa, H. M.; de Castro, E. V.; Microchem. J. 2010, 96, 180.

24. Amais, R. S.; Garcia, E. E.; Monteiro, M. R.; Nóbrega, J. A.; Fuel 2012, 93, 167.

25. Lima, A. S.; Silva, D. G.; Teixeira, L. S. G.; Environ. Monit. Assess. 2015, 187, 1.

26. Zmozinski, A. V.; de Jesus, A.; Vale, M. G. R.; Silva, M. M.; Talanta 2010, 83, 637.

27. Leite, C. C.; Zmozinski, A. V.; Vale, M. G. R.; Silva, M. M.; Anal. Methods 2015, 7, 3363.

28. Cunha, F. A. S.; Sousa, R. A.; Harding, D. P.; Cadore, S.; Almeida, L. F.; Araújo, M. C. U.; Anal. Chim. Acta 2012, 727, 34.

29. Capek, I.; Adv. Colloid Interface Sci. 2004, 107, 125.

30. Salager, J.; J. Surfactants Deterg. 2005, 8, 3.

31. Burguera, J. L.; Burguera, M.; Talanta 2012, 96, 11.

32. Pereira, T. C.; Conceição, C. A. F.; Khan, A.; Fernandes, R. M. T.; Ferreira, M. S.; Marques, E. P.; Marques, A. L. B.; Spectrochim. Acta, Part A 2016, 168, 60.

33. Chatzidaki, M. D.; Arik, N.; Monteil, J.; Papadimitriou, V.; Leal-Calderon, F.; Xenakis, A.; Colloids Surf., B 2016, 137, 146.

34. International Union of Pure and Applied Chemistry (IUPAC); Standard Methods for the Analysis of Oils, Fats and Derivatives, Blackwell Scientific Publications: Oxford, 1991. Available at http://old.iupac.org/publications/books/ISBN0632033371_ compress.pdf, accessed on October 30, 2017.

35. International Organization for Standardization (ISO); ISO 8294:1994; Animal and Vegetable Fats and Oils - Determination of Copper, Iron and Nickel Contents - Graphite Furnace Atomic Absorption Method, ISO, 1994. Available at https://www.iso. org/standard/15414.html, accessed on October 30, 2017.

36. Association of Official Analytical Chemists (AOAC); AOAC 990.05; Copper, Iron, and Nickel in Edible Oils and Fats, AOAC, 1992. Available at http://www.aoacofficialmethod.org/index. php?main_page=product_info\&cPath $=1 \&$ products_id=257, accessed on October 30, 2017.

37. American Oil Chemists' Society (AOCS); AOCS Official Method Ca 18b-91; Copper, Iron, and Nickel by Graphite Furnace 
Atomic Absorption Spectrophotometry, AOCS, 1998. Available at https://aocs.personifycloud.com/PersonifyEBusiness/ Default.aspx ?TabID $=251$ \&productId $=114588$, accessed on October 30, 2017.

38. Welz, B.; Sperling, M.; Atomic Absorption Spectrometry, $3^{\text {rd }}$ ed.; Wiley-VCH: Weinheim, Germany, 1999.

39. Kumarathasan, R.; Rajkumar, A. B.; Hunter, N. R.; Gesser, H. D.; Prog. Lipid Res. 1992, 31, 109.

40. Kittipongpittaya, K.; Salcedo, L.; McClements, D. J.; Decker, E. A. In Nanotechnology and Functional Foods: Effective Delivery of Bioactive Ingredients, $1^{\text {st }}$ ed.; Sabliov, C. M.; Chen, H.; Yada, R. Y., eds.; John Wiley \& Sons, Ltd: Chichester, 2015, p. 138.

41. Ke, P. J.; Ackman, R. G.; J. Am. Oil Chem. Soc. 1973, 50, 429.

42. Chaix, E.; Guillaume, C.; Guillard, V.; Compr. Rev. Food Sci. Food Saf. 2014, 13, 261.

43. Gunstone, F. D.; Fatty Acid and Lipid Chemistry; Chapman \& Hall: New York, 1996.

44. Association of Official Analytical Chemists (AOAC); Guidelines for Standard Method Performance Requirements; AOAC Official Methods of Analysis, 2016. Available at http:// www.eoma.aoac.org/app_f.pdf, accessed on October 30, 2017.
45. Thompson, M.; Ellison, S. L. R.; Wood, R.; Pure Appl. Chem. 2002, 74, 835 .

46. Cindric, I. J.; Zeiner, M.; Steffan, I.; Microchem. J. 2007, 85, 136.

47. Gonzálvez, A.; Ghanjaoui, M. E.; El Rhazi, M.; de la Guardia, M.; Food Sci. Technol. Int. 2010, 16, 65.

48. Tokay, F.; Bağdat, S.; Int. J. Food Sci. Technol. 2015, 50, 2694.

49. Buldini, P. L.; Ferri, D.; Sharma, J. L.; J. Chromatogr. A 1997, 789, 549.

50. Martín-Polvillo, M.; Albi, T.; Guinda, A.; J. Am. Oil Chem. Soc. 1994, 71, 347.

51. Sleeter, R. T.; J. Am. Oil Chem. Soc. 1981, 58, 239.

52. Ghazani, S. M.; Marangoni, A. G.; J. Am. Oil Chem. Soc. 2013, 90, 923.

53. Lamas, D. L.; Crapiste, G. H.; Constenla, D. T.; Food Sci. Technol. 2014, 58, 71 .

Submitted: August 11, 2017

Published online: November 3, 2017 